
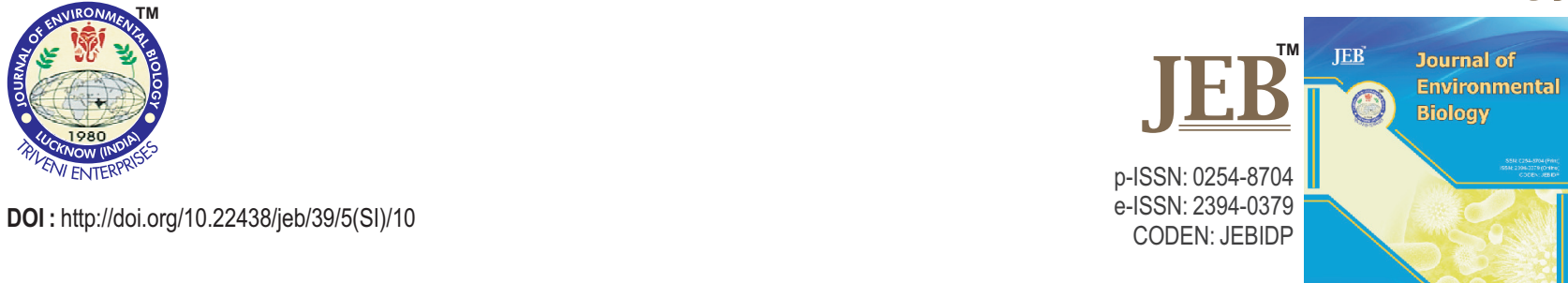

\title{
Food and feeding habits of Nemipterus japonicus and Nemipterus peronii from coastal water of Bintulu, Sarawak, South China Sea
}

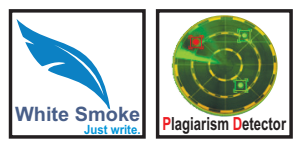

\section{Authors Info}

N. Tonnie', M.K. Abu Hena*, M. H. Idris' , A.H. Rajaee', S.M.N. $\mathrm{Amin}^{3}$ and M. H. Nesarul', ${ }^{1,4}$

'Department of Animal Science and Fishery, Faculty of Agriculture and Food Sciences, Universiti Putra Malaysia Bintulu Sarawak Campus-97008 Bintulu, Malaysia

${ }^{2} S$ chool of Fisheries and Aquaculture Sciences, Universiti Malaysia Terengganu, 21030 Kuala Terengganu, Malaysia

${ }^{3}$ Department of Aquaculture, Faculty of Agriculture, Universiti Putra Malaysia, 43400 UPM Serdang, Selangor, Malaysia ${ }^{4}$ Institute of Marine Sciences and Fisheries, University of Chittagong, Chittagong-4331, Bangladesh

*Corresponding Author Email : hena71@yahoo.com

Key words

Feeding habits Nemipterus japonicus Nemipterus peronii

Numerical method

Stomach fullness

Publication Info

Paper received : 22.04.2017

Revised received : 20.06.2017

Re-revised received : 05.07.2017

Accepted : 28.12.2017

\section{Abstract}

Aim: Knowing that feeding habit of fishes is important for ecosystem management and conservation purposes. In this regard, a total of 240 fish stomachs of each species of Nemipterus japonicas (11.9-26.0 $\mathrm{cm}$ in length) and Nemipterus peronii (11.6 $-25.3 \mathrm{~cm}$ in length) from the coastal area of Bintulu were examined monthly for one year from April 2013 to March 2014.

Methodology: Food items were analyzed using frequency of occurrence, numerical and fullness methods. Each species were grouped into three different length sized groups (large, medium and small). The degree of stomach fullness was classified into five categories (empty, one quarter full, half full, three quarter full and full).

Results: N. japonicus was an active feeder with a higher percentage $(38.03 \%)$ of full stomachs, while $N$. peronii was poor feeder with higher percentage (27.05\%) of one-quarter full stomachs. Diet composition contained seven major categories that included fish, crustaceans, molluscs, echinoderms, polychaetes, nematodes and unidentified food items. Crustaceans (mainly crabs) were preferred in both the $N$. japonicus and $N$. peronei at $13.54-35.71 \%$ of occurrence and $13.07-33.56 \%$, respectively. Food items in both the species varied with season with maximum in intermediate and minimum in wet season.

Interpretation: Findings revealed that $N$. japonicas and $N$. peronii are carnivorous, and may change their feeding habits from shrimp to crabs, and then to fish as they grow.
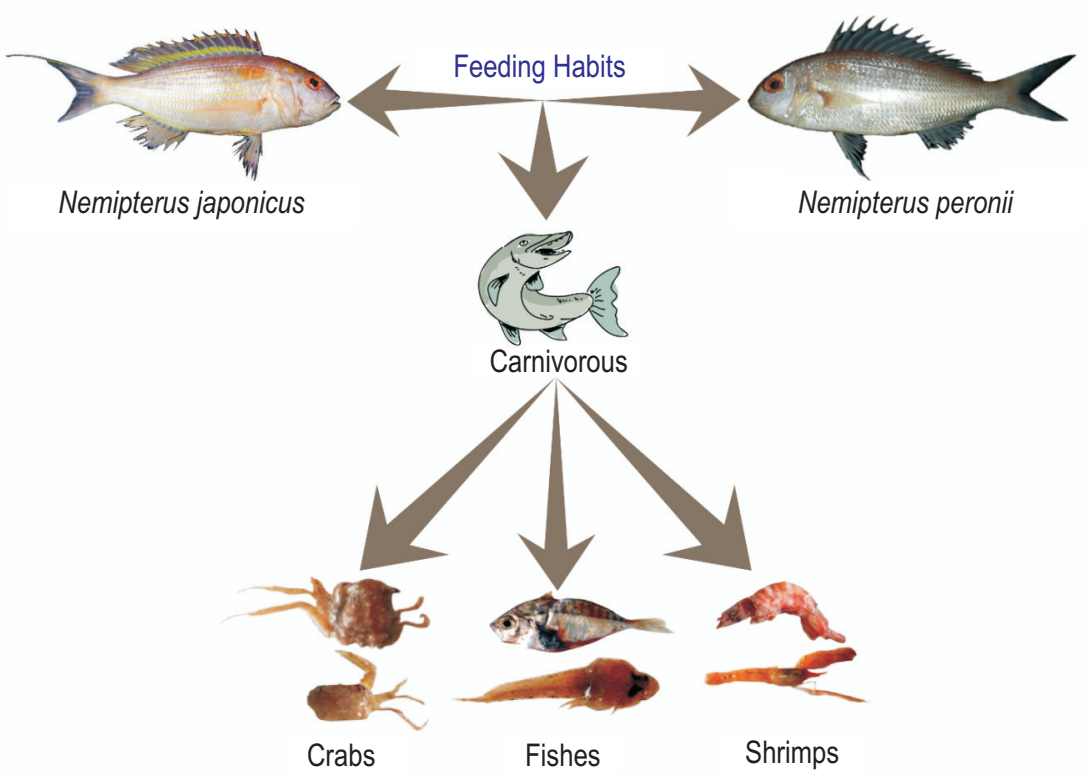


\section{Introduction}

Analyzing the stomach contents of fish provides information about their ecological niche, and has become a standard practice in fish ecology and trophic linkage research (Hyslop, 1980; Ibrahim et al., 2003). Several studies on the reproductive and feeding biology of many fish species have been conducted such as those in the Northern of Persian Gulf (Kerdgari et al., 2009), off Veraval (Gopal and Vivekanandan, 1991), the Jizan Region of the Red Sea (Bakhsh, 1994), off Visakhapatnam (Rajkumar et al., 2003) and off the Andhra-Orissa coast (Krishnamoorthi, 1971). In Indian water, analyses of stomach content of $N$. japonicus was carried out by Gopal and Vivekanandan (1991) and found that Acetes spp. are the preferred food items.

The Japanese threadfin bream, Nemipterus japonicas, is an economically important and trawled throughout the South China Sea (Russel, 1990). It has a pinkish body color, silvery below and 11-12 pale golden-yellow stripes along the body from behind the head to base of caudal fin. It has a single continuous dorsal fin, a long pectoral fin which reaching beyond level of anal fin and a caudal fin with filamentous extension. This species is widespread in the Indo-West Pacific ranging from East Africa, including the Persian Gulf and Red Sea and the Indo-Malay Archipelago (Russel, 1993). It inhabits shallow sandy or muddy bottoms at depths of 5.0-80.0 m. Another species, Nemipterus peronii is also trawled in commercial quantities in the Straits of Malacca and off Terengganu Coast in the South China Sea
(Russel, 1990; Said et al., 1994). It has a pinkish upper body, with 7 to 8 indistinct darker pink saddles reaching to or just below the lateral line. The lower part of the body is silvery with faint golden lines following each scale row. The species is distributed in West Pacific from Taiwan to Northern Australia and in Indian Ocean including the Andaman Sea, Bay of Bengal, Sri Lanka, Arabian Sea, Persian Gulf and Red Sea.

The aim of this research was to investigate the food items and feeding habits of $N$. japonicus and $N$. peronii from the coastal area of Bintulu, Sarawak, South China Sea. Such studies could be important in terms of ecosystem management and conservation. This is because determining the preferred food items of fish can provide a basis for understanding their trophic interactions in aquatic food webs. Moreover, this represents an integration of many important ecological components that includes behavior, condition, habitat use and interaction. It is anticipated that the findings of this research could be helpful to evaluate the ecological role of these two commercially important species, as well as to provide an understanding of its position in the food web structure and tropic linkage in the coastal waters of South China Sea.

\section{Materials and Methods}

The samples were collected from commercial fish landing site at Bintulu $\left(3^{\circ} 10^{\prime} 13.9^{\prime \prime} \mathrm{N} ; 113^{\circ} 02^{\prime} 22.9^{\prime \prime} \mathrm{E}\right)$ and Kuala Nyalau village $\left(3^{\circ} 38^{\prime} 26.9^{\prime \prime} \mathrm{N} ; 113^{\circ} 23^{\prime} 0.46^{\prime \prime} \mathrm{E}\right)$ from April 2013 to March 2014 (Fig. 1). Samples were immediately transported to the

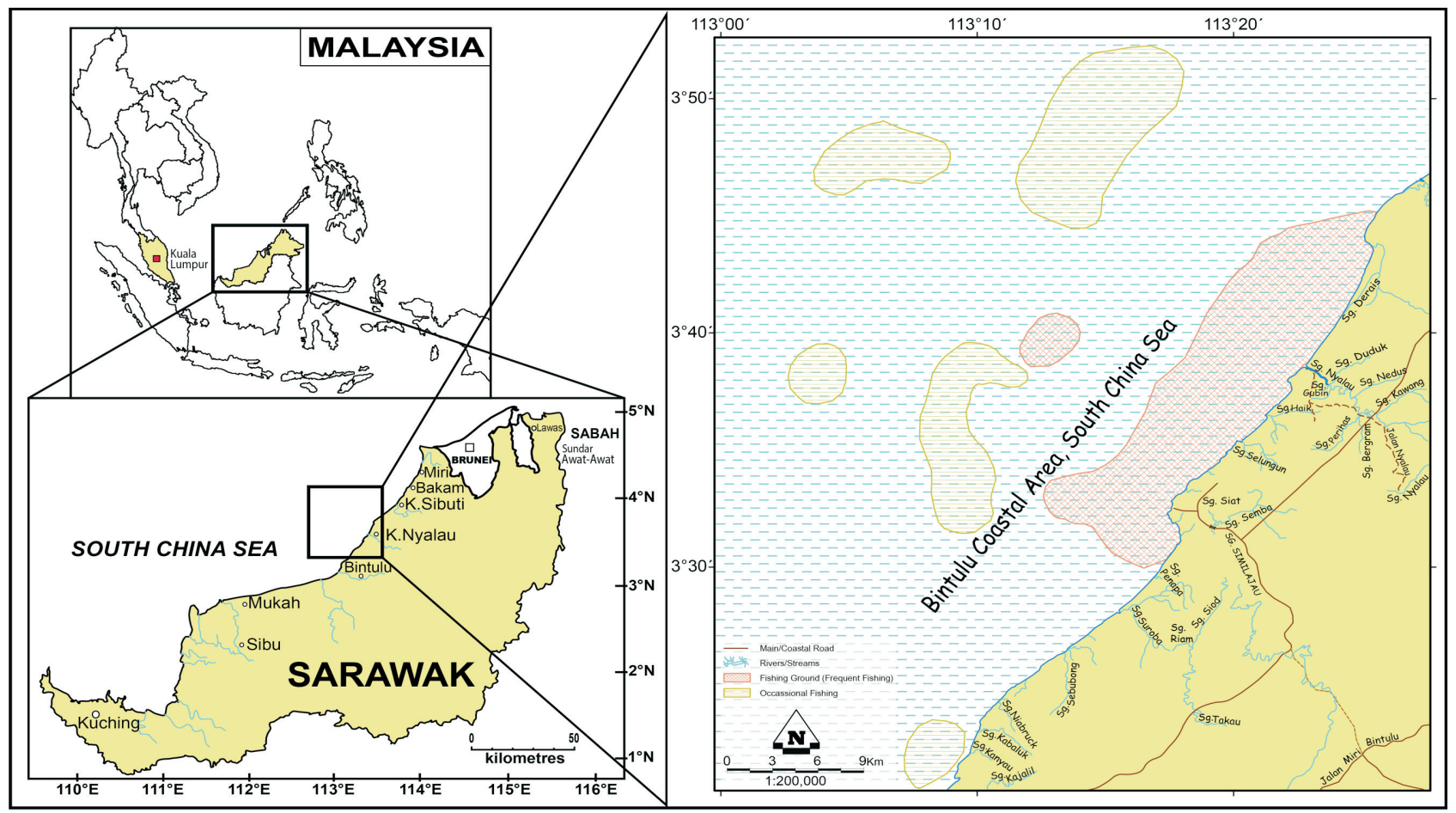

Fig. 1 : Location of the study area showing Bintulu coast in the South China Sea 
laboratory for further analysis. Total length (TL) of individual was measured from the tip of snout to the tip of caudal fin according to Vivekanandan and James (1986) using measuring board to the nearest $0.1 \mathrm{~cm}$. Body weight $(\mathrm{BW})$ was measured using electronic balance to the nearest $1.0 \mathrm{~g}$ accuracy. The fishes were dissected, the stomachs were removed and were preserved in $10 \%$ formalin. The degree of stomach fullness was recorded by cutting the stomach open and all the contents were placed onto a petri dish for identification. Analysis was done using frequency of occurrence and numerical methods according to Hyslop (1980) and Hynes (1950). The occurrence of food items was expressed as the percentage of total number of stomachs containing food, while the number of each food items was expressed as the percentage of total number of food items found in the stomach. The stomach fullness was divided into five categories that included empty, one quarter full, half full, three quarter full or full.

Stomach content analysis : The percentage frequency of occurrence $\left(F_{p i}\right)$ and percentage numerical abundance $\left(C_{i}\right)$ for each type of prey was calculated by the formula given below (Chrisafi et al., 2007).

$$
\mathrm{Fpi}=(\mathrm{N} 1 \mathrm{i} / \mathrm{Np}) \times 100
$$

where, $N_{1 i}$ is the number of stomachs in which food item $i$ was found while $\mathrm{N}_{p}$ is the number of non-empty stomachs.

$$
\begin{aligned}
& \mathrm{Ci}=\operatorname{nix} 100 \\
& \sum \mathrm{m} n
\end{aligned}
$$

where, $n_{i}$ is the number of ith food item and $m$ is the number of food items.

\section{Results and Discussion}

Stomach fullness in different length classes of $N$. japonicus and $\mathbf{N}$. peronii : The total length for N. japonicus and N. peronii ranged from 11.9-26.0 to $11.6-25.3 \mathrm{~cm}$, respectively. The specimens were grouped into three-sized groups, namely small $(11.0-15.9 \mathrm{~cm})$, medium $(16.0-20.9 \mathrm{~cm})$ or a large size $(>21 \mathrm{~cm})$ group. The feeding intensity for both fish species varied with different length classes (Table 1). The smaller sized group of $N$. japonicus showed a higher percentage of one quarter full (36.98\%), while the medium and large sized groups showed a higher percentage of full stomachs at $26.35 \%$ and $38.03 \%$, respectively. For $N$. peronii, the smaller sized group showed a higher percentage of one quarter full $(51.04 \%)$, while medium sized group had a higher percentage of half full stomachs $(24.95 \%)$. The larger sized group was found to have a higher percentage of full stomachs $(46.81 \%)$.

Monthly variation in stomach fullness : The percentage of $\mathrm{N}$. japonicus with empty stomachs varied with the season (Fig. 2). Stomach was not found to be empty in November, which was found higher in January (35\%). Full stomachs were observed to be higher in April (40\%), October (40\%) and February (45\%). This showed that the feeding activity was high during these three months. For N. peronii, empty stomachs increased from October to January (Fig. 3). The percentage of empty stomachs in $N$. peronii was found to be lower in September $(0 \%)$, which became higher in January $(35 \%)$. The amount of full stomachs was observed to be higher in April (40\%) and October (40\%) for $\mathrm{N}$. peronii. The number of full stomachs decreased from April to June and then after gradually increased from July to October (intermediate season). Fish with full stomachs further decreased from November to February (wet season) up to the lower percentage $(5 \%)$.

Diet composition in different length classes : The stomachs of smaller sized groups of $N$. japonicus consisted of 16 types of food items (Table 2). The results showed the most consumed food items were crabs and shrimp at the same percentage of occurrence at $13.54 \%$. For the numerical method, foraminifera had the highest percentage $(24.43 \%)$ by number. For the medium sized group of $N$. japonicus with a length class of $16-20.9 \mathrm{~cm}, 158$ stomachs were examined and 20 stomachs were empty. There were 18 food items observed and the most frequent were crabs (22.91\%). Based on the analyzed data, crabs were found to be the most important diet $(24.48 \%)$ by number, which was followed by shrimp (10.00\%). For the large sized group of $N$. japonicus with a length class $>21 \mathrm{~cm}$, a total of 43 stomachs were examined with 4 stomachs that were empty and 16 food items were observed. Crabs were dominant food found in the stomachs of $N$. japonicus

\begin{tabular}{|c|c|c|c|c|c|c|c|c|}
\hline \multirow[t]{2}{*}{ Stomach fullness } & \multicolumn{4}{|c|}{ N. japonicus (\%) } & \multicolumn{4}{|c|}{ N. peronii $(\%)$} \\
\hline & $11.0-15.9 \mathrm{~cm}$ & $16.0-20.9 \mathrm{~cm}$ & $>21 \mathrm{~cm}$ & $\begin{array}{l}\text { All length } \\
\text { classes }\end{array}$ & $11.0-15.9 \mathrm{~cm}$ & $16.0-20.9 \mathrm{~cm}$ & $>21 \mathrm{~cm}$ & $\begin{array}{l}\text { All length } \\
\text { classes }\end{array}$ \\
\hline Full & 9.13 & 26.35 & 38.03 & 24.50 & 4.17 & 13.57 & 46.81 & 21.52 \\
\hline Three quarter full & 21.43 & 20.30 & 23 & 21.59 & 5.21 & 23.05 & 13.18 & 13.81 \\
\hline Half full & 24.29 & 25.39 & 17.42 & 22.37 & 13.54 & 24.95 & 14.98 & 17.82 \\
\hline One quarter full & 36.98 & 14.84 & 14.09 & 21.97 & 51.04 & 20.24 & 12.58 & 27.95 \\
\hline Empty & 8.17 & 13.12 & 7.42 & 9.57 & 26.04 & 18.19 & 12.45 & 18.89 \\
\hline
\end{tabular}
with a length class $>21 \mathrm{~cm}$ at $20.83 \%$ percentage by occurrence.

Table 1 : Percentage of stomach fullness in N. japonicus and N. peronii from Bintulu coastal water, Sarawak 


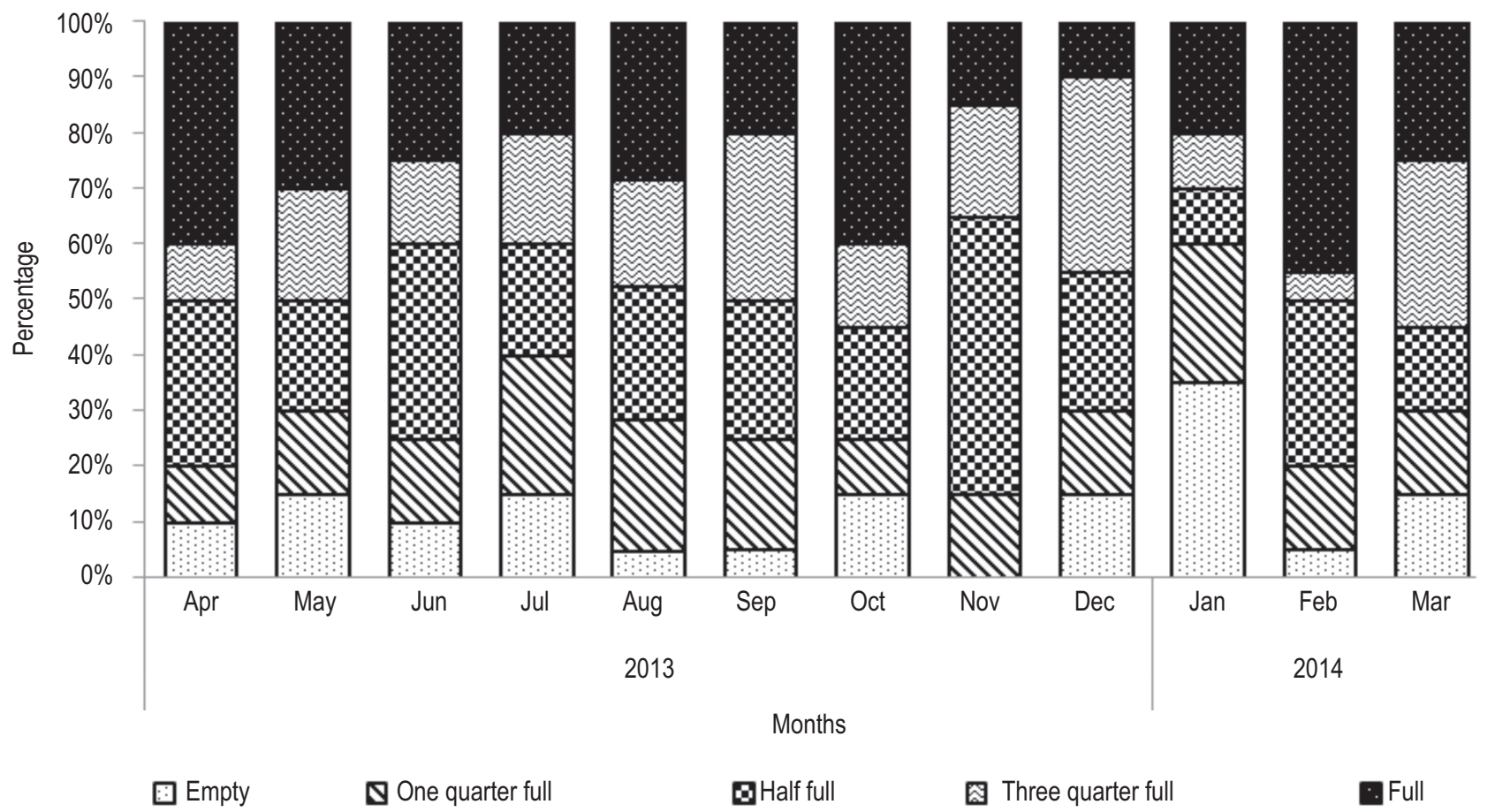

Fig. 2 : Seasonal variation frequency of $N$. japonicus stomach fullness categories in Bintulu coast, South China Sea

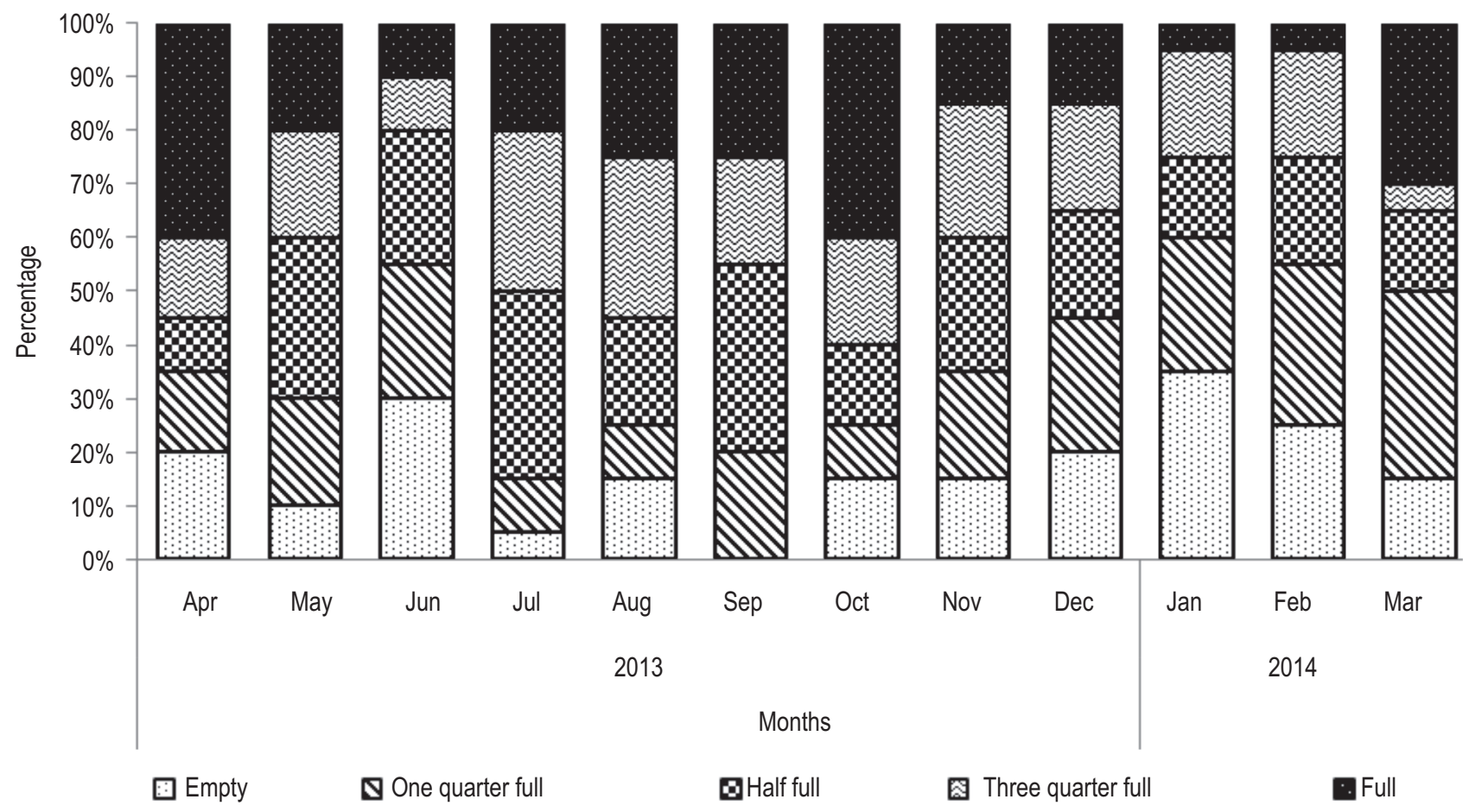

Fig. 3 : Seasonal variation frequency of $N$. peronii stomach fullness categories in Bintulu coast, South China Sea

Based on the numerical method, shrimp were present at a higher percentage (30.22\%) compared to other food items.
Twelve food items were observed with shrimp (22.58\%) that showed the highest percentage of occurrence (Table 3). For the numerical method, crab was the most consumed food item 
Table 2 : Diet composition of $N$. japonicus with different length classes in the coastal area of Bintulu, Sarawak

\begin{tabular}{|c|c|c|c|c|c|c|}
\hline \multirow[t]{3}{*}{ Food categories } & \multicolumn{6}{|c|}{ Length class } \\
\hline & \multicolumn{2}{|c|}{$11.0-15.9 \mathrm{~cm}$} & \multicolumn{2}{|c|}{$16.0-20.9 \mathrm{~cm}$} & \multicolumn{2}{|c|}{$>21 \mathrm{~cm}$} \\
\hline & $\mathbf{F}_{\mathrm{pi}}$ & $\mathrm{C}_{\mathrm{i}}$ & $F_{p i}$ & $\mathrm{C}_{\mathrm{i}}$ & $\mathbf{F}_{\mathrm{pi}}$ & $C_{i}$ \\
\hline Fishes & 4.17 & 2.27 & 11.17 & 9.66 & 10.42 & 9.89 \\
\hline \multicolumn{7}{|l|}{ Crustaceans } \\
\hline Crab & 13.54 & 13.07 & 22.91 & 24.48 & 20.83 & 16.48 \\
\hline Shrimp & 13.54 & 11.93 & 12.01 & 10.00 & 11.46 & 30.22 \\
\hline Mantis shrimp & 6.25 & 3.41 & 6.42 & 5.86 & 8.33 & 8.79 \\
\hline Lobster & 2.08 & 1.14 & 0.56 & 0.34 & 2.08 & 1.10 \\
\hline Isopod & 1.04 & 0.57 & 1.68 & 1.03 & 1.10 & 1.65 \\
\hline Amphipod & 8.33 & 4.55 & 8.94 & 9.48 & 3 & 1.65 \\
\hline Copepod & 3.13 & 6.25 & 1.12 & 1.72 & - & - \\
\hline Ostracod & 4.17 & 2.84 & 0.56 & 0.52 & 6.25 & 6.59 \\
\hline \multicolumn{7}{|l|}{ Molluscs } \\
\hline Bivalve & 7.29 & 4.55 & 4.19 & 2.59 & 5.21 & 3.30 \\
\hline Gastropod & 6.25 & 3.98 & 3.07 & 2.59 & 5.21 & 3.30 \\
\hline $\begin{array}{l}\text { Cephalopod } \\
\text { Echinoderms }\end{array}$ & - & - & 3.63 & 2.76 & 6.25 & 3.30 \\
\hline Ophiuroidea & 10.42 & 10.23 & 8.38 & 6.21 & 4.17 & 3.30 \\
\hline Echinoidea & - & - & 0.84 & 0.52 & - & - \\
\hline Foraminifera & 6.25 & 24.43 & 2.51 & 8.28 & 3.13 & 4.40 \\
\hline Polychaetes & 6.25 & 3.98 & 4.75 & 5.17 & 2.08 & 1.65 \\
\hline Nematodes & 2.08 & 1.14 & 2.23 & 1.55 & 2.08 & 1.10 \\
\hline Unidentified food items & 5.21 & 5.68 & 5.03 & 6.55 & 7.29 & 3.85 \\
\hline
\end{tabular}

$\mathrm{F}_{\mathrm{pi}}:$ Percentage frequency of occurrence, $\mathrm{C}_{\mathrm{i}}:$ Percentage of number

with the percentage of $21.05 \%$, followed by shrimp and mantis shrimp accounting for $15.79 \%$. For the medium sized group of $N$. peronii with a length class of $16.0-20.9 \mathrm{~cm}, 144$ stomachs were examined and 24 were found to be empty. There were 18 food items observed and the most preferred was crab with an occurrence of $35.71 \%$. The most dominant food items among all were crabs $(33.56 \%)$ followed by ostracods $(26.82 \%)$, shrimp and foraminifera $(5.71 \%)$, respectively, while fishes accounted for $5.54 \%$.

Monthly variation in diet composition : The percent occurrence of food items in $N$. japonicus varied throughout the year. Fish, crabs, shrimp and ophiuroidea were present throughout the study period. The percentage of fish was higher during May (21.95\% of occurrence) and lower in November (6.25\%). Mantis shrimp was observed as food items to fish throughout the year, except for April and May. For the numerical method (Fig. 4), crabs were also found to be the most preferred food item among $N$. japonicus throughout the year as the percentage of crabs were higher from June to September as well as November and January. The highest percentage by number of crabs were consumed in November (47.77\%). In April and February, shrimps were the dominant food item, followed by ostracod in May, mantis shrimp in October and foraminifera in December and March.
Studies showed that crab was the most important food item for $N$. peronii among all food items consumed. Fish, crabs and shrimps were present throughout the year. The percent of occurrence of crab remained higher throughout the year, except in April. The highest percent of occurrence (52.78\%) of crab was found in July, while the percentage of fish was higher $(20.00 \%)$ in October and lower (3.92\%) in November. For the numerical method (Fig. 5), from May to August crab was the most dominant food item in stomach of $N$. peronii, with the highest percentage in July $(73.91 \%)$. In September, the percentage of crabs sharply decreased as $N$. peronii consumed more on ophiuroidea $(42.16 \%)$ whereas from October to March, N. peronii continued to consume more on crabs.

Feeding habits and strategies of Nemipterus spp. have been studied using stomach content analysis (Krishnamorthi, 1971; Afshari et al., 2013; Bakhsh, 1994; Raje, 2002; Said et al., 1994; Gopal and Vivekanandan, 1991; Gurlek et al., 2010; Ibrahim et al., 2003; Joslin, 2009); these studies discovered an opportunistic feeding behavior and marked inclinations for small shellfish (Gopal and Vivekanandan, 1991; Joslin, 2009). Crabs, shrimp, mantis shrimp, lobsters, amphipods, copepods and ostracods were present in the stomachs of both the fish, which is in agreement with the findings of Krishnamoorthi (1971) and Afshari et al. (2013). Studies by Bakhsh (1994) and Raje (2002) 


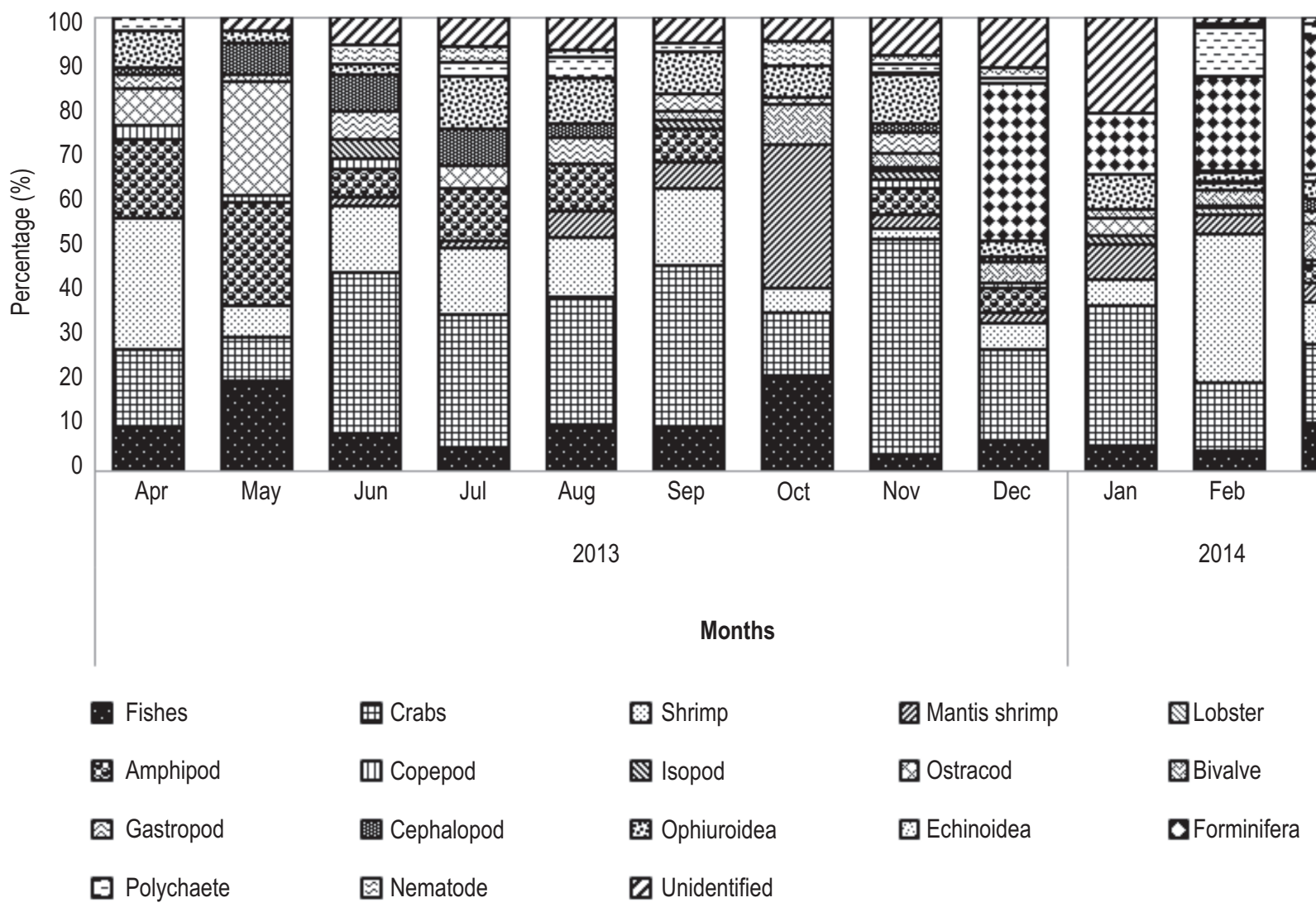

Fig. 4 : Seasonal variation percentage of $N$. japonicus stomach food items by number in Bintulu coast, South China Sea

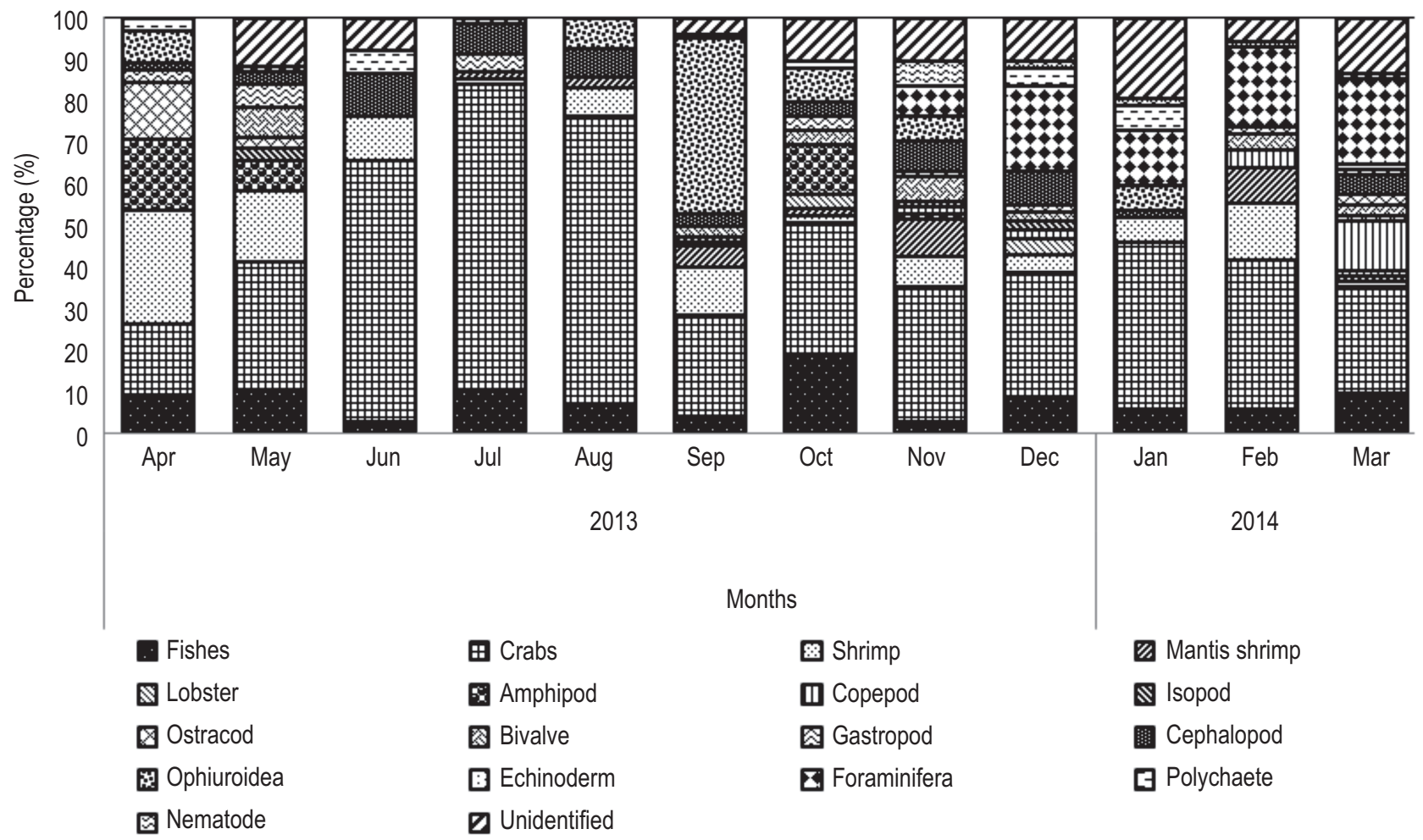

Fig. 5 : Seasonal variation percentage of N. peronii stomach food items by number in Bintulu coast, South China Sea 
Table 3 : Diet composition of $N$. peronii with different length classes in the Coastal area of Bintulu, Sarawak

\begin{tabular}{|c|c|c|c|c|c|c|}
\hline \multirow[t]{3}{*}{ Food categories } & \multicolumn{6}{|c|}{ Length class } \\
\hline & \multicolumn{2}{|c|}{$11.0-15.9 \mathrm{~cm}$} & \multicolumn{2}{|c|}{$16.0-20.9 \mathrm{~cm}$} & \multicolumn{2}{|c|}{$>21 \mathrm{~cm}$} \\
\hline & $\mathrm{F}_{\mathrm{pi}}$ & $C_{i}$ & $F_{p i}$ & $C_{i}$ & $\mathbf{F}_{\mathrm{pi}}$ & $C_{i}$ \\
\hline Fishes & - & - & 11.11 & 5.54 & 15.03 & 10.27 \\
\hline \multicolumn{7}{|l|}{ Crustaceans } \\
\hline Crab & 19.35 & 21.05 & 35.71 & 33.56 & 26.59 & 27.38 \\
\hline Shrimp & 22.58 & 15.79 & 6.35 & 5.71 & 9.83 & 7.60 \\
\hline Mantis shrimp & 9.68 & 15.79 & 4.37 & 1.90 & 2.31 & 1.52 \\
\hline Lobster & 3.23 & 3.51 & 0.40 & 0.17 & 1.16 & 0.76 \\
\hline Isopod & - & - & 0.79 & 0.35 & 1.90 & 1.90 \\
\hline Amphipod & - & - & 1.59 & 1.04 & 1.52 & 1.52 \\
\hline Copepod & 3.23 & 8.77 & 1.19 & 1.56 & 3.42 & 3.42 \\
\hline Ostracod & 3.23 & 12.28 & 1.98 & 26.82 & 1.90 & 1.90 \\
\hline \multicolumn{7}{|l|}{ Molluscs } \\
\hline Bivalve & 3.23 & 1.75 & 2.78 & 1.21 & 5.20 & 3.80 \\
\hline Gastropod & 3.23 & 1.75 & 3.57 & 1.56 & 3.47 & 4.56 \\
\hline Cephalopod & 9.68 & 5.26 & 8.33 & 3.81 & 6.36 & 4.18 \\
\hline \multicolumn{7}{|l|}{ Echinoderms } \\
\hline Ophiuroidea & - & - & 5.95 & 4.50 & 4.05 & 13.69 \\
\hline Echinoidea & - & - & 0.40 & 0.17 & 0.58 & 0.38 \\
\hline Foraminifera & 6.45 & 3.51 & 3.97 & 5.71 & 4.05 & 6.84 \\
\hline Polychaetes & 3.23 & 1.75 & 1.98 & 1.04 & 1.16 & 0.76 \\
\hline Nematodes & - & - & 1.59 & 0.69 & 1.73 & 1.52 \\
\hline Unidentified food items & 12.90 & 8.77 & 7.94 & 4.15 & 7.51 & 7.22 \\
\hline
\end{tabular}

$\mathrm{F}_{\mathrm{pi}}:$ Percentage frequency of occurrence; $\mathrm{C}_{\mathrm{i}}:$ Percentage of number

found that $N$. japonicus is mainly carnivorous and predominately feed on crustaceans, polychaetes, teleosts, molluscs, annelids and echinoderms. In Indian waters, $N$. japonicus preferred to feed on crustaceans, especially Acetes spp. (Gopal and Vivekanandan, 1991) while $N$. peronii mainly consumed crustaceans, especially crabs, which is in consistent with the findings of Said et al. (1994).

The percent occurrence of shrimp decreased as the length increased in $N$. peronii, but not in $N$. japonicas. Vivekanandan (1990) reported that in shallow waters, $N$. japonicas were observed to prey mostly on juvenile prawn, whereas those in deeper waters mostly consumed fish and crabs. This revealed that the smaller sized group of $N$. peronii mostly inhabits shallow coastal waters compared to the medium and larger sized groups. Concurring to the scavenging concept, the probability of prey capture is a function of prey density, size, total visibility and motion (Lazzaro, 1987), thus it could probably be the case for the present finding. Variations in the food composition from different length classes also provide information where fish changes their feeding habits from shrimp to crabs and then to fish as it grows. The medium and larger sized groups tended to consume fish compared to the smaller sized group. Preference for size selection by commercially important species has been advised in previous studies (Abu Hena and Hishamuddin, 2012; Bartulovic et al., 2004). However, in the present study, the size- selective preference may be related to season and prey availability, as well as length class distribution of the fish.

In general, according to the classification by Marichamy (1970), the medium and large sized groups of N. japonicus are active feeders with the higher percentage of full stomachs whereas the small sized $N$. japonicus were poor feeders. For $N$. peronii, the small sized group was also a poor feeder while the medium was moderate feeder and the large size was active feeder (Table 1). Krishnamorthi (1971) stated that the degree of stomach fullness did not increase with the size of the fish, however the type of food did. The seasonal composition of Nemipterus stomach contents was affected by monsoonal activities. Usually, prey items were higher in the intermediate season compared to wet season in this coastal water, indicating that Nemipterus were following an opportunistic feeding behavior, each time targeting the more available prey items whenever present. Both $N$. japonicus and $N$. peronii had a similar diet as they occupied the same ecological niches. Both species were found as predacious carnivores that exhibited a tendency of feeding at the bottom, as evidenced by the presence of benthic organisms such as brittle star, crabs, gastropods and polychaetes in their stomach. Bachok et al. (2004) also found teleosts, cephalopods, crustaceans, echinoderms and molluscs in the stomachs of carnivorous adult marine fish in Malaysian marine waters. 
The present study found that crustaceans and other slow moving animals in the sea were the major food items for both $N$. japonicus and $N$. peronii. Similar results were obtained for Nemipterus randalli in the eastern Mediterranean sea (Gurlek et al., 2010), Nemipterus marginatus in South China Sea (Ibrahim et al., 2003) and Nemipterus delagoae in Tamil Nadu, India (Joslin, 2009). Hajisamae et al. (2006) noted two carnivorous Sillaginid sp. in the southern part of the South China Sea that mainly feed on polychaetes and other benthic organisms. The species Trichiurus margarites consumed crustaceans, fish and molluscs in Beibu Gulf, South China Sea (Yan et al., 2012). This study has provided information about the effects of season on feeding, as well as fish size on food preference. Similar food preference by the larger fish may give rise to competition within the same trophic level or potentially cannibalism on smaller conspecifics (Qasim, 1972). In addition, any change in the prevalence of these carnivorous species could have a large impact on the crustacean diversity and abundance in any coastal ecosystems (Gurlek et al., 2010), which should be further investigated for fisheries management.

\section{Acknowledgments}

Authors acknowledge the Department of Animal Science and Fishery, UPM Campus Bintulu Sarawak for providing facilities and Ministry of Higher Education, Malaysian Government for providing funds through Knowledge Transfer Programme (KTP), Project No. K-edu/100 (UPM-12) and UPM/700-2/1/GP. IPS/2016/9493500.

\section{References}

Abu Hena, M.K. and O. Hishamuddin: Food selection preference of different ages and sizes of black tiger shrimp, Penaeus monodon, Fabricius, in tropical aquaculture ponds in Malaysia. Afri. $\mathrm{J}$. Biotechnol., 11,6153-6159 (2012).

Afshari, M., T. Valinassab, J. Seifabadi and E. Kamaly: Age determination and feeding habits of Nemipterus japonicus (Bloch, 1791) in the Northern Oman Sea. Iran. J. Fishe. Sci, 12, 248-264 (2013).

Bakhsh, A.A.: The biology of threadfin bream, Nemipterus japonicus (Bloch) from the Jizan Region of the Red Sea. J. Mar. Sci., 7, 179189 (1994).

Bachok, Z., M.I. Mansor and R.M. Noordin: Diet composition and food habits of demersal and pelagic marine fishes from Terengganu waters, East coast of Peninsular Malaysia. NAGA, World Fish Center Quarterly., 27, 3-4 (2004).

Bartulovic, V., D. Lucic, A. Conides, B. Glamuzina, J. Dulcic, D. Hafner and M. Batistic: Food of sand smelt, Atherina boyeri Risso, 1810 (Pisces: Atherinidae) in the estuary of the Mala Neretva River (Middle-Eastern Adriatic, Croatia). Scientia Marina, 68, 597-603 (2004).

Chrisafi, E., P. Kaspiris and G. Katselis: Feeding habits of sand smelt (Atherina boyeri, Risso 1810) in Trichonis Lake (Western Greece). J. Appl. Ichthyol., 23, 209-214 (2007).

Gopal, C. and E. Vivekanandan: Threadfin bream fishery and biology of Nemipterus japonicus off Veraval. Ind. J. Fish., 38, 97-102 (1991).

Gurlek, M., S. Erguden, D. Yaglioglu, F. Turan, S. Demirhan, M. Gungor, B. Ozbalcilar and T. Ozcan: Feeding habits of Indo-Pacific species
Nemipterus randalli (Russel, 1986) (Nemipteridae) in Iskenderun Bay, Eastern Mediterranean Sea. Rapports et Procès-Verbaux des Réunions Commission Internationale pour l'Exploration Scientifique de la Mer Méditerranée, 39, 539 (2010).

Hajisamae, S., P. Yeesin and S. Ibrahim: Feeding ecology of two sillaginid fishes and trophic interrelations with other co-existing species in the southern part of South China Sea. Environ. Biol. Fis., 76, 167-176 (2006).

Hynes, H.B.N.: The food of freshwater sticklebacks (Gasterosteus aculeatus and Pygosteus pungitius), with a review of methods used in studies of the food of fishes. J. Ani. Ecol., 19, 36-58 (1950).

Hyslop, E.J.: Stomach contents analysis, a review of new methods and their application. J. Fish Biol., 17, 411-429 (1980).

İbrahim, S., M. Muhammad, M.A. Ambak, M.Z. Zakaria, A.S. Mamat, M. M. İsa and S. Hajisamae: Stomach contents of six commercially important demersal fishes in the South China Sea. Tur. J. Fishe. Aqu. Sci., 3, 11-16 (2003).

Joslin, P.J.: Some aspects of biology of Threadfin bream Nemipterus delagoae from Tuticorin waters. J. Mar. Biol. Associ. India, 51, 231$233(2009)$.

Kerdgari, M., T. Valinassab, S. Jamili, M.R. Fatemi and F. Kaymaram: Reproductive biology of the Japanese threadfin bream, Nemipterus japonicus, in the Northern of Persian Gulf. J. Fishe. Aqu. Sci., 4, 143-149 (2009).

Krishnamoorthi, B.: Biology of the threadfin bream, Nemipterus japonicus (Bloch). Ind. J. Fishe., 18, 1-21(1971).

Lazzaro, X.: A review of planktivorous fishes: Their evolution, feeding behaviours, selectivities, and impacts. Hydrobiology, 146, 97-167 (1987).

Marichamy, R.: Food and feeding habits of the spotted herring, Herklotsichtys punctatus (Ruppell) from the Andaman sea. Ind. J. Fishe., 17, 159-168 (1970).

Qasim, S.Z.: The dynamics of food and feeding habits of some marine fishes. Ind. J. Fishe., 19, 11-28 (1972).

Raje, S.G.: Observations on the biology of Nemipterus japonicus (Bloch) from Veraval. Ind. J. Fishe., 49, 433-440 (2002).

Rajkumar, U., K.N. Rao and H.J. Kingsly: Fishery, biology and population dynamics of Nemipterus japonicus (Bloch) off Visakhapatnam. Ind. J. Fishe., 50, 319-324 (2003).

Russell, B.C.: A review of the threadfin breams of the genus Nemipterus (Nemipteridae) from Japan and Taiwan, with description of a new species. Japan. J. Ichthyol., 39, 295-310 (1993).

Russell, B.C.: Nemipterid fishes of the world (threadfin breams, whiptail breams, monocle breams, dwarf monocle breams and coral breams). Family Nemipteridae. An annonated and illustrated catalogue of nemipterid species known to date. FAO Fisheries synopsis no.125, FAO (1990).

Said, M., M. Zaki, M. Mohsin, A. Khair and M.A. Ambak: Food and feeding habits of Nemipterus peronii (Valenciennes) from the South China Sea. Perta. J. Trop. Agricult. Sci., 17, 125-131 (1994).

Vivekanandan, E.: Distribution pattern of threadfin breams along North Tamil Nadu and South Andhra Coasts. Ind. J. Fisher., 37, 269-280 (1990).

Vivekanandan, E. and D.B. James: Population dynamics of Nemipterus japonicus (Bloch) in the trawling grounds off Madras. Ind. $\mathrm{J}$. Fisher., 33, 145-154 (1986).

Yan, Y., J. Chen, H. Lu, G. Hou and J. Lai: Feeding habits and ontogenetic diet shifts of hairtail, Trichiurus margarites in the Beibu Gulf of South China Sea. Acta Ecol. Sini., 32, 18-25 (2012). 